\title{
Comparative Effect of Core Stabilization Exercise and Active Video Gaming on Dynamic Balance in Elderly Female People: a Single- Blind Randomized Controlled Clinical Trial
}

\author{
Chatwalai Sonthikul, M.Sc. ${ }^{1}$, Nurulhuda Hadhoh, B.Sc. ${ }^{2}$, Nurulhuda Madeeyoh, B.Sc. ${ }^{3}$, \\ Aungsuma Ponlakarn, B.Sc. ${ }^{4}$, Natthawat Dolthamsiri, B.Sc. ${ }^{5}$ \\ 'Department of Physical Therapy, Faculty of Medicine, Prince of Songkla University, Hat Yai, Songkhla 90110, Thailand. \\ ${ }^{2}$ Sabayoi Hospital, Saba Yoi, Songkhla 90210, Thailand. \\ ${ }^{3}$ Raman Hospital, Raman, Yala 95140, Thailand. \\ ${ }^{4}$ Fort Thanarat Hospital, Pran Buri, Prachuap Khiri Khan 77160, Thailand. \\ ${ }^{5}$ Hatyai Chivasuk Health Promotion Center, Hat Yai, Songkhla 90110, Thailand. \\ Received 22 October 2020 • Revised 17 February 2021 • Accepted 12 March 2021 • Published online 16 June 2021
}

\begin{abstract}
:
Objective: The elderly have a decrease in muscle power and cognitive functions, leading to a higher risk of falling. The core stabilization exercise is a standard exercise for the elderly, but is considered as non-interesting and has no immediate feedback. On the other hand, active video gaming is new technology, more interesting and provides immediate feedback. Thus, the objective was to compare the effectiveness of core stabilization exercise (CSE) and active video gaming (AVG) on dynamic balance, core and lower limb muscle strength and reaction time in elderly people.

Material and Methods: This study was a single-blind randomized controlled trial design; conducted from January to April, 2019. The participants were 34, healthy, elderly patients; who were randomly assigned to either the CSE group $(n=17)$ or AVG group $(n=17)$. All participants received a training program consisting of 60 minutes, 3 times a week, for 6 weeks. The CSE group received a core stabilization exercise program, while the AVG group received video gaming with balance control on a moveable platform (Sensamove ${ }^{\circledR}$, the Netherlands). The participants were assessed for dynamic balance, core and lower limb muscle strength, and reaction time at pre-, two, forth, and sixth week.
\end{abstract}

Contact: Chatwalai Sonthikul, M.Sc.

Department of Physical Therapy, Faculty of Medicine, Prince of Songkla University, Hat Yai, Songkhla 90110, Thailand.

E-mail: chatwalai.s@gmail.com

This is an open access article under the CC BY-NC-ND license

(http://www.jhsmr.org/index.php/jhsmr/about/editorialPolicies\#openAccessPolicy).

J Health Sci Med Res 2022;40(1):53-65 doi: $10.31584 /$ jhsmr.2021820 www.jhsmr.org 
Results: The AVG group showed superior and significant difference to the CSE group in dynamic balance after forth $(p-$ value $=0.004 ; 95 \%$ confidence interval $(\mathrm{Cl}),-0.94$ to -0.11$)$ and sixth week ( $p$-value $=0.001 ; 95 \% \mathrm{Cl},-1.22$ to -0.25 ) of training, and reaction time after forth $(p-v a l u e=0.028 ; 95 \% \mathrm{Cl},-37.89$ to -0.24$)$ and sixth week of training $(p-v a l u e=$ 0.026; $95 \% \mathrm{Cl},-72.08$ to -10.13$)$. However, within group comparison, after sixth weeks of training, the CSE group had significantly increased in core ( $p$-value $=0.020 ; 95 \% \mathrm{Cl}, 1.01$ to 21.55$)$ and lower limb muscle strength ( $p-v a l u e=0.008$; $95 \% \mathrm{Cl},-2.68$ to -0.39$)$. In addition, the AVG group had significantly increased in dynamic balance ( $p-v a l u e=0.001 ; 95 \%$ $\mathrm{Cl},-2.18$ to -0.66 ), lower limb muscle strength ( $p$-value $=0.001 ; 95 \% \mathrm{Cl},-2.38$ to -0.66$)$, and reaction time ( $p-$ value $=$ $0.007 ; 95 \% \mathrm{Cl},-120.99$ to -22.64$)$.

Conclusion: Active video gaming showed better effectiveness than the core stabilization exercise in both dynamic balance and reaction time. Between before and after six weeks of training, the core stabilization exercise increased in core and lower limb muscle strength. In addition, active video gaming increased in dynamic balance, lower limb muscle strength and reaction time. So, active video gaming can be added in generic rehabilitation for improvement of muscle strength, reaction time and balance.

Keywords: active video gaming, core stabilization exercise, dynamic balance, elderly, lower limb muscle strength

\section{Introduction}

Advancements in economic and medical development have increased longevity in humans, which has led to an increase in the proportion of elderly people around the world; including Thailand. ${ }^{1}$ Thailand has 11 million elderly people, or $16.5 \%$ of its population, and enter into an era of an aging society as of $2021 .^{1}$ The elderly have deterioration in their sensory systems (for example, vestibular, visual, somatosensory) and their cognitive systems (central nervous system and their musculoskeletal system) that affect balance control during activities of daily living. ${ }^{2-6}$ The muscle mass of the elderly, whom are aged over 60 years, is reduced by more than $3.0-8.0 \%$ per year. ${ }^{7}$ Leg strength declines by $2.8 \%$ in women and $3.6 \%$ in men per year; however, the average muscle strength of women is lower than men. ${ }^{8}$ Reduction in muscle strength and cognitive functions lead to a higher risk of falling among the elderly. ${ }^{9}$ According to statistics from the World Health Organization, those with an age of more than 65 years have risk of falling at 28-35 percent. ${ }^{10}$ Falling in the elderly is a major problem, which can lead to hospital admission, and is associated with functional decline in activities of daily living. ${ }^{11}$ Therefore, reduction of fall risk is important, and one of the prevention methods of fall is physical activity ${ }^{5,12}$

From a systematic review in $2019^{12}$, it was found that many types of exercise; composed of resistance and aerobic exercise, balance training, $\mathrm{T}-\mathrm{bow}^{\odot}$ and wobble board training, aerobic step and stability ball training, adapted physical activity and Wii Fit training can improve balance and prevent falls in the elderly. There is also another type of exercise that improves balance in the elderly; namely, the core stabilization exercise (CSE). ${ }^{13}$

The CSE is widely used in sport for improving balance and postural control. The "core" has been described as the "powerhouse", for the foundation of all limb movement, with the diaphragm as the roof, the hip girdle and the pelvic floor musculature as the bottom, the abdominals in the front, and paraspinal and gluteal muscles 
in the back. ${ }^{14,15}$ Core muscles work as a unit to stabilize the spine and body, with and without limb movement. Elderly age reduces core muscle strength, which in turn affects balance control. ${ }^{16}$ Previous studies found that CSE improves both static and dynamic balance, and the quality of life in elderly women after 6 -weeks of training. ${ }^{17}$ There are some feedback devices; such as a pressure biofeedback or manual palpation, which allows the subject to recognize the correct exercise during CSE.

Nowadays, there are new technology-based techniques to encourage activities for the elderly; such as active video games (AVG). ${ }^{18,19}$ They provide immediate visual as well as auditory feedback on the player's performance, which creates an enjoyable, motivational atmosphere and social interaction. ${ }^{20}$ Furthermore, it appears to be quite promising for strength and balance training in the elderly after 6 weeks of training; however, there was no control group for comparison. ${ }^{21}$ According to a study by Heiden and Lajoie in $2010^{22}$, they found that game based biofeedback improved functional balance more than the chair exercise program in the elderly after 8 weeks. Many, recent studies have also reported on CSE, or AVG in the elderly; however, few comparative studies between CSE and AVG on dynamic balance in the elderly have been reported. Therefore, the purpose of this study was to examine the effect of CSE and AVG on dynamic balance, core and lower limb muscle strength and reaction time in healthy, elderly people. The results of this study can be used for development of a generic program to improve balance in the elderly.

\section{Material and Methods}

A randomized controlled trial study (Figure 1), with a blind assessor, was conducted at the physical therapy department, faculty of medicine, Prince of Songkla University; from January to April, 2019. This study was designed to be assessor-blinded, so as to reduce bias as much as possible. The assessor did not perform the exercise program, did not know as to which program the participant received, and asked only simple questions.

The participants of this study were thirty-four, interested community-dwelling elderly women, from the brochure in Hatyai, Songkhla, Thailand. The elderly were of an 'early', old age; between 60 and 69, able to walk independently without any assistive device, had no vestibular and visual problems, nor cognitive impairment: having a Thai Mental State Examination score of more than 23, no lumbar surgery (for instances; laminectomy, discectomy) in 1 year, or suffered a fall within 1 month before participating were included in this study. Exclusion criteria of this study were: having experienced participation in regular balance training (for example. Taichi, or yoga) within the past 6 months, and having had a neurological defect (examples; stroke, traumatic brain injury, dementia or Parkinson's disease), musculoskeletal (examples: herniated nucleus pulposus, spondylosis and spinal stenosis), or cardiovascular problems (such as, unstable angina or uncontrolled hypertension), that affected the exercise program. The participants gave informed consent to participate in the study after the procedures were explained. This study was approved by the ethics committee of the Human Research Ethic Committee (HREC), Faculty of Medicine, Prince of Songkla University (EC. 61-359-30-2).

The sample size was calculated from our pilot study of 10 participants, using the formula as described, and estimated on the basis of dynamic balance measured on timed up and go test at six-weeks, assuming 80.0\% power, $5.0 \%$ of significance, and a $20.0 \%$ dropout rate, to detect a clinically, meaningful difference between groups; a minimum total sample size of 30 was required for this study.

$$
n_{\text {group }}=\frac{\left(Z_{1-\frac{\alpha}{2}}+Z_{1-\beta}\right)^{2}\left[\sigma_{A V G}^{2}+\frac{\sigma_{\frac{C S E}{2}}}{\frac{n_{A V G}}{n_{C S E}}}\right.}{\mu_{A V G}-\mu_{C S E}{ }^{2}}
$$






Figure 1 CONSORT flowchart of this study 
The participants were randomly allocated to either; the CSE or the AVG group, using computed block randomized allocation, with block sizes of 2, 4 and 6 for balance between groups $(A B, B A, A A B B, A B A B, B A A B$, BABA, BBAA, ABBA, AABB, AB). Both groups received an exercise program for 60 minutes, 3 times per week, for 6 weeks. The program consisted of 20 minutes for stretching exercises, before and after training, and 40 minutes for the CSE or AVG, depending on each assigned group. Muscle stretching consisted of 4 poses: pectorals muscles, gluteus maximus muscles, hamstring and calf muscle, and lower back muscles. Each muscle was stretched for 3 times and held for 15 seconds/time.

The CSE program was modified from a previous study suitable for Thai elderly people..$^{23,24}$ It was a home program, with the physical therapist teaching and checking for the correctness for each pose, before training at each level at the physical therapy department. During the training program, the researcher checked the correctness, and any problems with the exercise via telephone messages and a log book. There were three levels (Table 1) of the CSE program (Figure 2), which would progress in difficulty every 2 weeks.

Table 1 The level of core stabilization exercise program

\begin{tabular}{|c|c|}
\hline Level & Pose \\
\hline Level 1 & $\begin{array}{l}\text { Abdominal hollowing ( } 5 \text { seconds * } 10 \text { times), bridg- } \\
\text { ing ( } 5 \text { seconds * } 10 \text { times), lower trunk rotation (5 } \\
\text { seconds * } 10 \text { times), straight leg raise ( } 5 \text { seconds * } \\
10 \text { times), crunch ( } 5 \text { seconds * } 10 \text { times), and oblique } \\
\text { crunch ( } 5 \text { seconds * } 10 \text { times) }\end{array}$ \\
\hline Level 2 & $\begin{array}{l}\text { Abdominal hollowing ( } 5 \text { seconds * } 10 \text { times), bridg- } \\
\text { ing ( } 5 \text { seconds * } 10 \text { times), lower trunk rotation (5 } \\
\text { seconds * } 10 \text { times), crunch ( } 5 \text { seconds * } 10 \text { times), } \\
\text { plank ( } 10 \text { seconds * } 10 \text { times), and seat marching (5 } \\
\text { seconds * } 5 \text { times) }\end{array}$ \\
\hline Level 3 & $\begin{array}{l}\text { Abdominal hollowing ( } 5 \text { seconds * } 10 \text { times), bridg- } \\
\text { ing ( } 5 \text { seconds * } 10 \text { times), lower trunk rotation ( } 5 \\
\text { seconds * } 10 \text { times), plank ( } 10 \text { seconds * } 10 \text { times), } \\
\text { seat marching ( } 5 \text { seconds * } 5 \text { times), and wall squat } \\
\text { (5 seconds * } 10 \text { times) }\end{array}$ \\
\hline
\end{tabular}

The AVG train with balance control on a moveable platform (Miniboard; Sensamove ${ }^{\circledR}$, Utrecht, the Netherlands) at the physical therapy department. The signal from the moveable platform, by shifting weight on the balance board, interacted with a video game on the television. The participants tried to move the moveable platform in anteriorposterior or medio-lateral directions, to control the ball on the screen through a maze, or to a target. During the first 1-4 weeks, the participants exercised with a balance board in a sitting position; whereas, in weeks 5-6 the participants exercised with a mini-board in a standing position, with a standard rubber accessory that allowed tilting by $10^{\circ}$ in all directions; additionally there was a walker in front of them for protection against falling (Figure 3 ). There were three levels of the programs (Table 2), and these would progress in difficulty every 2 weeks.

Table 2 The level of active video gaming program

\begin{tabular}{ll}
\hline Level & Pose \\
\hline Level 1 & $\begin{array}{l}\text { Free exercise range } 30^{\circ} \text { (5 minutes), BMS range } 30^{\circ} \\
8 \text { directions, Training } 1-18\end{array}$ \\
Level 2 & $\begin{array}{l}\text { BMS range } 30^{\circ} 8 \text { directions, Static balance range } \\
30^{\circ} 8 \text { directions, Extra 1-22 }\end{array}$ \\
Level 3 & $\begin{array}{l}\text { Free exercise range } 30^{\circ} \text { (5 minutes), Static balance } \\
\text { range } 30^{\circ} 8 \text { directions, Static balance range } 30^{\circ} 8 \\
\text { directions, Training 1-18 }\end{array}$ \\
&
\end{tabular}

The assessor in this study was a physical therapist, whom had 8 years of experience. Intrarater reliability was excellent in the timed up and go test $(I C C=0.95)$, prone bridge test $(I C C=0.89)$, and the five time sit to stand test (ICC=0.87). In addition, interrater reliability, with the specialist, was excellent in the timed up and go test (ICC= $0.91)$, prone bridge test $(I C C=0.85)$, and the five time sit to stand test $(\mathrm{ICC}=0.87)$. Assessments were performed at pre-training (T0), $2^{\text {nd }}$ week after training (T1), $4^{\text {th }}$ week after training (T2), and $6^{\text {th }}$ week after training (T3). 

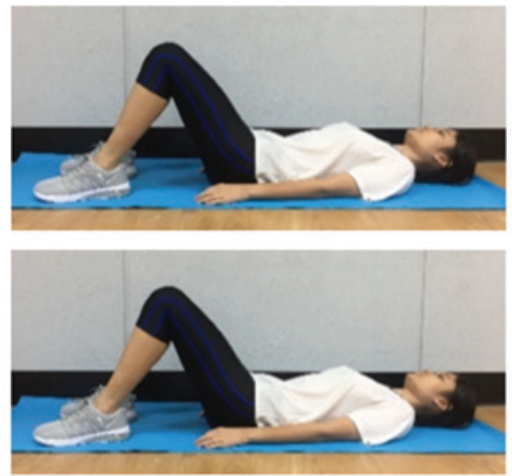

Abdominal contraction
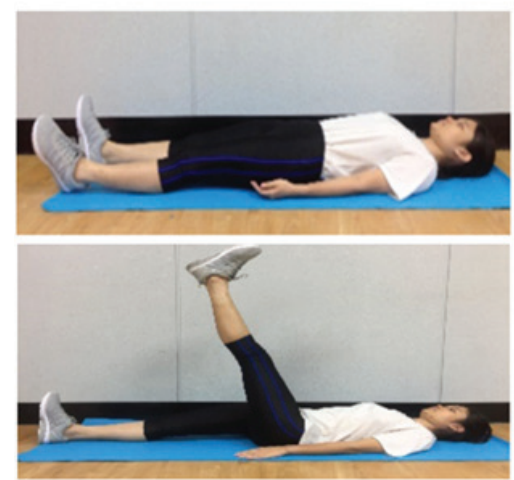

Straight leg raise (SLR)
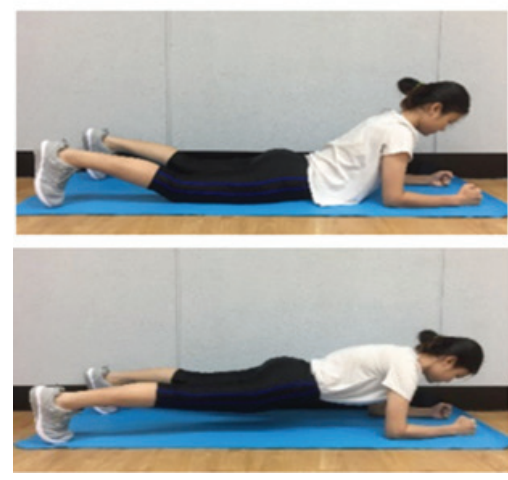

Plank
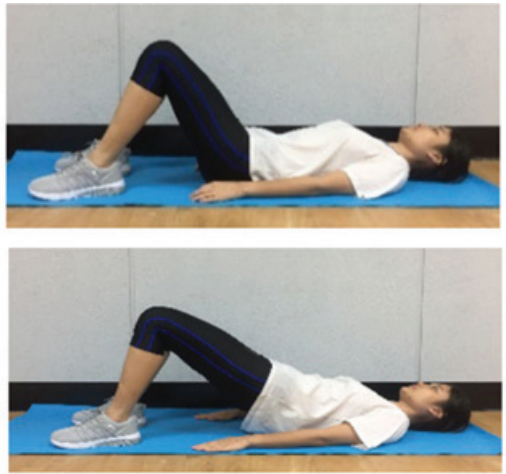

Bridging
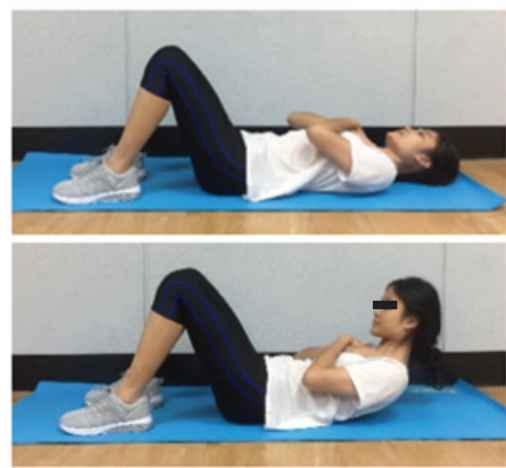

Crunch

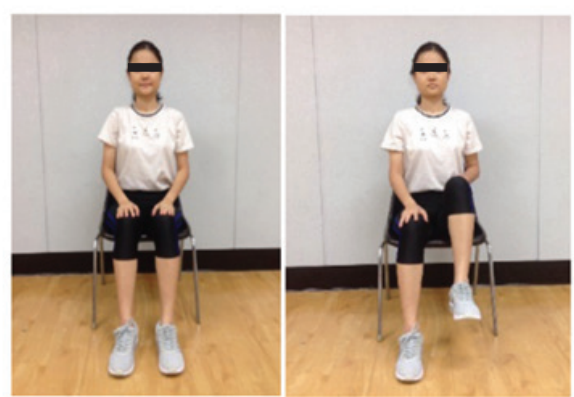

Seated marching
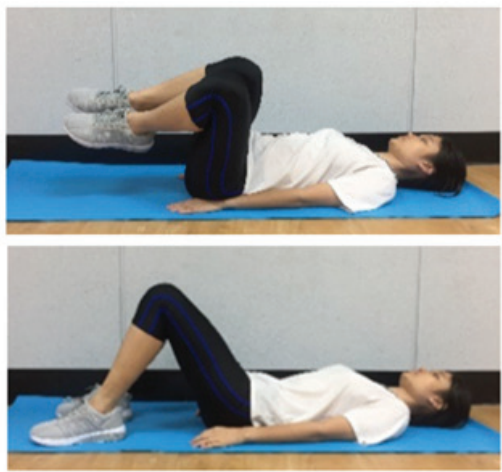

Lower trunk rotation
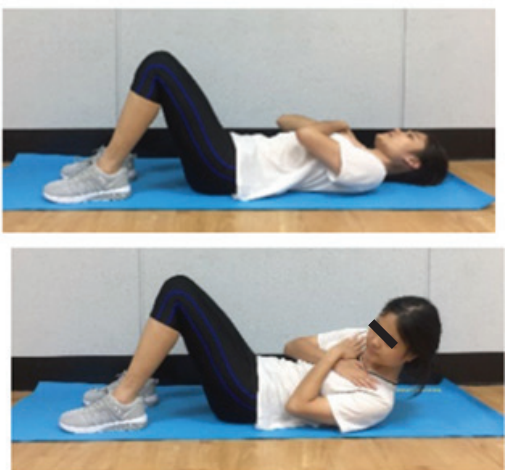

Oblique crunch

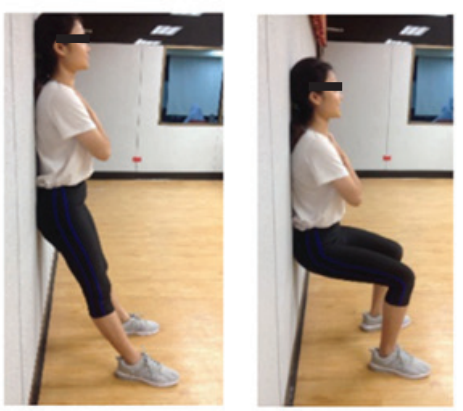

Wall squat

Figure 2 Core stabilization exercise program 

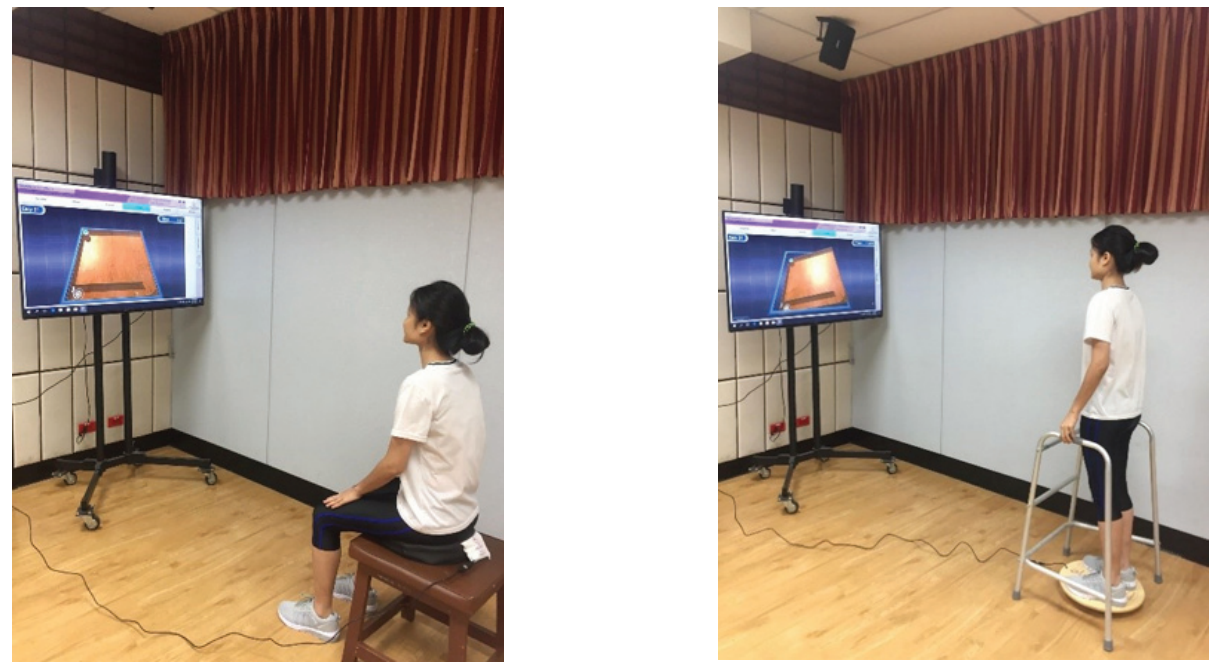

Figure 3 Active video gaming with Sensamove ${ }^{\circledR}$, Utrecht, the Netherlands

The Timed up and go test was used to evaluate dynamic balance and falling risk. Minimal, detectable change of the test is 2.42 seconds in Thai individuals with Alzheimer disease. ${ }^{25}$ The participants sat on the chair, wearing regular shoes, with both feet on the floor. When the participant heard the signal "go", they stood up and walked as quickly and safely as possible for a 3-meter distance, turned around the cone, and returned back to sit down on the same chair. The time from the point the buttocks left the chair until they were seated was recorded using a stopwatch. The average time of three tests was calculated for data analysis.

The Prone bridge test was used to test core muscles strength. This test could be conducted easily in all locations with little equipment. The participants were in a prone, lying position, with both forearms on the floor and with their elbows flexed at approximately 90 degrees. Both feet were apart, at shoulder width. When the participants were told to "start", they lifted their hips off the floor, while keeping their torso and legs straight. The participants were encouraged to hold this position for as long as possible. ${ }^{26}$ The assessor measured the time that the participant could actually do this in seconds, and stopped the watch when the trunk was not parallel to the body, by visual of the video.
The participants could rest between tests when fatigued or tired. The average time of three tests was calculated for data analysis.

The five time sit to stand test was used to evaluate the strength of the leg muscles. ${ }^{27}$ When the assessor said "Start", the participants performed the "sit to stand" as fast as possible, 5 times without any hand support. The assessor would start the stopwatch when the participant started to get up from the chair, and would stop the time when the participant was seated; after the completion of five repetitions. The least time of three-time tests was used for data analysis.

The Reaction test was used to assess reaction time of the participants. This is used to assess risk of falling in the elderly. ${ }^{28}$ The reaction test tool for Thai motorist's licenses was used in this study. Participants sat on a chair, and their dominant foot was placed on a pedal. When the assessor pressed the start button, the reaction time tool would display a green light, once the light changed to red, the participants pressed the pedal as quickly as possible. The assessor recorded time in milliseconds (ms), and used the least time of three-time tests for data analysis. 
Statistical Package for Social Sciences version 23.0 was used for statistical analysis: the analysis was by intention to treat. The normal distribution of data was analyzed by Shapiro-Wilk test. All values were presented with median and interquartile range (IQR); except, demographic data which was presented with mean \pm standard deviation. MannWhittney $U$ test, for different change values of independent data, was performed to verify the intergroup differences; whereas, the paired data was analyzed by Wilcoxon signed rank test. Statistical significance was set at $p$-value $<0.05$. Furthermore, effect of the treatment was investigated by the effect size (ES) of each variable. The effect size was calculated to compare pre-training (TO), $2^{\text {nd }}$ week after training $(\mathrm{T} 1), 4^{\text {th }}$ week after training $(\mathrm{T} 2)$, and $6^{\text {th }}$ week after training (T3), within groups and between groups, for each variable following this equation:

$$
\text { Effect size }=\frac{\text { IMean1-Mean } 2 I}{\text { Standard deviation 2 }}
$$

The value of ES were classified as: minimal $(0.20 \leq E S<0.50)$, moderate $(0.50 \leq E S<0.80)$, and large effect size $(E S \geq 0.80)$.

\section{Results}

Table 3 shows average age, height, weight, and body mass index (BMI) of the CSE group $(n=17)$ as 63.47 years, $59.42 \mathrm{~kg}, 156.63 \mathrm{~cm}$, and $22.75 \mathrm{~kg} / \mathrm{m}^{2}$, while those in the AVG group ( $n=17)$ were 63.07 years, $53.40 \mathrm{~kg}, 155.87$ $\mathrm{cm}$, and $21.92 \mathrm{~kg} / \mathrm{m}^{2}$. There was no significant difference between the groups regarding age, weight, height, or BMI (p-value>0.050).

Table 4 shows significant difference of changing values between the CSE group and AVG group in timed up and go test at the fourth (T2) ( $p$-value=0.004; 95\% confidence interval $(\mathrm{Cl}),-0.94$ to -0.11$)$, and the sixth week (T3) ( $p$-value $=0.001 ; 95 \% \mathrm{Cl},-1.22$ to -0.25$)$. Furthermore, there was significant difference between groups at the fourth (T2) ( $p$-value=0.028; 95\% Cl, -37.89 to -0.24 ), and the sixth week (T3) (p-value=0.026; 95\% Cl, -72.08 to -10.13$)$ in reaction time.

Table 3 Demographic of the participants in this study $(n=3)$

\begin{tabular}{llll}
\hline Parameters & $\begin{array}{l}\text { Core stabilization } \\
\text { exercise group }(\mathbf{n}=17)\end{array}$ & $\begin{array}{l}\text { Active video } \\
\text { gaming group }(\mathbf{n}=17)\end{array}$ & $\mathbf{p}$-value \\
\hline Age $($ year) & $63.47 \pm 2.97$ & $63.07 \pm 1.71$ & 0.656 \\
Weight $(\mathrm{kg})$ & $(61.82,65.11)$ & $(62.12,64.01)$ & 0.100 \\
& $59.42 \pm 10.99$ & $53.40 \pm 8.17$ & $(48.87,57.93)$ \\
Height $(\mathrm{cm})$ & $(53.33,65.51)$ & $155.87 \pm 7.57$ & 0.729 \\
& $156.63 \pm 3.75$ & $(151.68,160.06)$ & 0.633 \\
\hline
\end{tabular}

Mean \pm standard deviation ( $95 \%$ confidence interval), tested statistically by Independent t-test 
Table 5 shows the changes over time of dynamic balance, core and lower limb muscle strength and reaction time in both groups. Program compliance was excellent in both the CSE and AVG groups; with $95.0 \%$ and $96.0 \%$ completion of the training sessions, respectively. The CSE program showed a significant increase in time for the prone bridge test, at the sixth week (ES, 0.48; p-value= $0.020 ; 95 \% \mathrm{Cl}, 1.01$ to 21.55$)$, and decreased time for five time sit to stand test at the second $(E S=0.83 ; p-v a l u e=$ $0.012 ; 95 \% \mathrm{Cl},-2.53$ to -0.22 ), fourth ( $E S=0.85$; $p$-value, $0.011 ; 95 \% \mathrm{Cl},-2.71$ to -0.27 ), and sixth week (ES=0.89; p-value $=0.008 ; 95 \% \mathrm{Cl},-2.68$ to -0.39 ). The AVG group showed a significant decrease in time for the timed up and go test at the second (ES=0.67; $p$-value $=0.019 ; 95 \% \mathrm{Cl}$, -2.55 to -0.20 ), fourth ( $E S=0.89 ; p$-value $=0.001 ; 95 \% \mathrm{Cl}$, -1.67 to -0.56$)$, and sixth week $(E S=1.22 ; p-v a l u e=0.001$; $95 \% \mathrm{Cl},-2.18$ to -0.66$)$. Furthermore, It showed a significant decrease in time for five time sit to stand test at the second $(E S=0.51 ; p$-value $=0.016 ; 95 \% \mathrm{Cl},-2.92$ to -0.24), fourth ( $E S=0.94, p$-value $=0.001 ; 95 \% \mathrm{Cl},-2.39$ to -0.62), and sixth week ( $E S=0.81 ; p$-value $=0.001 ; 95 \% \mathrm{Cl}$, -2.38 to -0.66$)$, and a decreased reaction time at the fourth $(E S=0.74 ; p$-value $=0.020 ; 95 \% \mathrm{Cl},-68.20$ to -8.21 ) and sixth week $(E S=0.85 ; p-$ value $=0.007 ; 95 \% \mathrm{Cl},-120.99$ to $-22.64)$.

\section{Discussion}

The aim of this study was to compare the effectiveness of the core stabilization exercise and active video gaming on dynamic balance, core and lower limb muscle strength, and reaction time in female elderly. The results revealed significant difference between CSE and AVG in dynamic balance and reaction times after the fourth and sixth week of training. All participants in this study did not have balance impairment at pre-training, because they had a time of less than 8 seconds. $^{29}$ Even though, the change value of timed up and go test in both groups was 


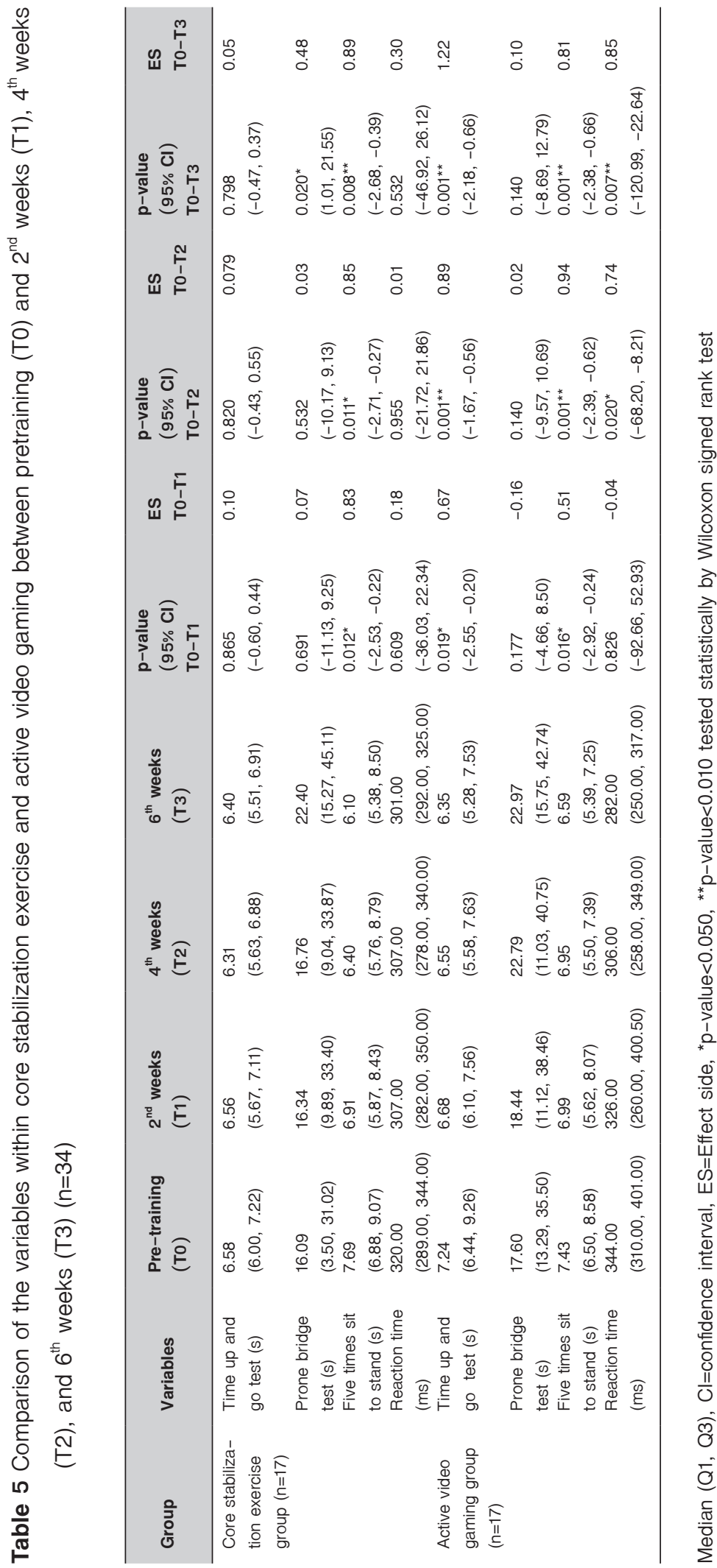


less than the minimal detectable change, the effect size of change in the AVG group was large, while the CSE was small. The results of this present study were consistent with those of Heiden and Lejoje $\mathrm{e}^{22}$; indicating an improvement of balance and reaction time, after games-based biofeedback training more so than for the chair exercise program. Furthermore, it was also consistent with that of Song and Park in $2016^{30}$, which found improvement of dynamic balance in the elderly after neck and trunk stabilization exercises with biofeedback more so than only neck and trunk stabilization exercises. This was consistent with the study by Laver et al. ${ }^{31}$, which found improvement of dynamic balance measured with timed up and go test in hospitalized, older adults after using an interactive gaming program more so than conventional physiotherapy. The AVG group was superior to the CSE group, due to participants in the AVG receiving biofeedback concerning their movements all the time. This would activate many sensory receptors, which relay crucial information within the body. ${ }^{32-34}$ It helped the participants in the AVG group to be aware of body scheme. Furthermore, AVG encouraged them to transfer weight in different directions through the games; this in turn helped the participants in AVG to improve their reaction time and brought about improved dynamic balance. ${ }^{33}$

The CSE program did not significantly improve dynamic balance; however, it significantly improved core and lower limb muscle strength after 6 weeks of training. The results from this study are consistent with a previous study, that found significant increase in core and lower limb muscles strength after core stabilization programs in healthy, middle-aged people. ${ }^{35}$ In addition, it was consistent with the study of Granacher et al. in $2012^{36}$; wherein, the increase in trunk muscle strength was found after core stability strength training in the elderly. The CSE program of this study included bridging, lower trunk rotation, straight leg raises, seat marching and wall squats. As the core muscles are linked to the spine, pelvis and thigh, when the core muscles work it also results in the increase of leg function. ${ }^{36,37}$ However, the poses in this program were in the static position, or center of mass moving in base of support; so, it is not helpful for improving dynamic balance.

In our study, the AVG group demonstrated significant improvement in dynamic balance, lower muscle strength and reaction time after 6 -weeks of training. This was consistent with previous studies, indicating an improvement of dynamic balance after neck and trunk stabilization exercises with pressure biofeedback in the elderly. ${ }^{30}$ Furthermore, It was also consistent with that of Cho et al. in 2014, which found improvement in balance after virtual reality training in the elderly. ${ }^{38}$ The study of Sato et al. in 2015, also reported significant improvement in lower limb muscle strength being found after 24-sessions of Exergame using Kinect ${ }^{\circledR} .{ }^{39}$ The games in this study stimulated the motor response for task specific training, and cognition in solving the game. AVG promoted implicit learning, where it was less affected than explicit learning in the elderly. ${ }^{21}$ Furthermore, AVG consists of training in a sitting or standing position requiring the work of the leg muscles, in order to control a moveable platform to interact with a video game. This in turn, led to the improvement of lower limb muscle strength, reaction time, cognition and prevention of falling risk in the elderly. ${ }^{40}$ The limitations of this study included no follow ups being taken, and mainly measuring only the quantities of balance and muscle strength. In addition, further studies should assesse the long-term effects, and should consider investigating other parameters; such as, muscle activity, kinematics, kinetics and walking abilities.

\section{Conclusion}

Regarding the results of this study, it seemed that applying the core stabilization exercise could improve core and lower limb muscle strength. While, active video gaming could not only improve lower limb muscle strength and reaction time, but also increase dynamic balance. Finally, 
it is highly recommended that using active video gaming can increase motivation, and decrease the risk of falls in the elderly. The findings of this study may have broader clinical implications for understanding the effects of core stabilization exercise and active video gaming in the elderly. In addition, they should provide significant information of improvements of muscle power and balance, which may be beneficial for geriatric rehabilitation programs.

\section{Acknowledgement}

The authors would like to express their appreciation to the dear participants for their willingness to participate in this study, and to Ms. Pornnit Wattanapisitkul for the revision of this manuscript.

\section{Funding sources}

This study was supported by the Faculty of Medicine, Prince of Songkla University.

\section{Conflict of interest}

There is no conflict of interest.

\section{References}

1. Prasartkul $P$, Vapattanawong $P$, Kanchanachitra M, Chuanwan S, Rittirong J, Jaratsit S, et al. Situation of the thai elderly 2016. Bangkok: Foundation of Thai Gerontology Research and Development Institute; 2017.

2. Dunsky A. The Effect of Balance and coordination exercises on quality of life in older adults: a mini-review. Front Aging Neurosci 2019;11:318.

3. West CG, Gildengorin G, Haegerstrom-Portnoy G, Schneck ME, Lott $L$, Brabyn JA. Is vision function related to physical functional ability in older adults?. J Am Geriatr Soc 2002;50:136-45.

4. Hof PR, Morrison JH. The aging brain: morphomolecular senescence of cortical circuits. Trends Neurosci 2004;27:60713.

5. Jensen J, Nyberg L, Rosendahl E, Gustafson Y, Lundin-Olsson L. Effects of a fall prevention program including exercise on mobility and falls in frail older people living in residential care facilities. Aging Clin Exp Res 2004;16:283-92.
6. Stevens JA, Olson S. Reducing falls and resulting hip fractures among older women. MMWR Recomm Rep 2000;49:3-12.

7. Volpi E, Nazemi R, Fujita S. Muscle tissue changes with aging. Curr Opin Clin Nutr Metab Care 2004;7:405-10.

8. Goodpaster BH, Park SW, Harris TB, Kritchevsky SB, Nevitt $M$, Schwartz AV, et al. The loss of skeletal muscle strength, mass, and quality in older adults: the health, aging and body composition study. J Gerontol A Biol Sci Med Sci 2006;61: 1059-64.

9. Thomas E, Battaglia G, Patti A, Brusa J, Leonardi V, Palma A, et al. Physical activity programs for balance and fall prevention in elderly: a systematic review. Medicine (Baltimore) 2019;98: e16218.

10. Sharif SI, Al-Harbi AB, Al-Shihabi AM, Al-Daour DS, Sharif RS. Falls in the elderly: assessment of prevalence and risk factors. Pharm Pract (Granada) 2018;16:1206.

11. Tinetti ME, Williams CS. The effect of falls and fall injuries on functioning in community-dwelling older persons. J Gerontol A Biol Sci Med Sci 1998;53:112-9.

12. Carter ND, Kannus P, Khan KM. Exercise in the prevention of falls in older people: a systematic literature review examining the rationale and the evidence. Sports Med 2001;31:427-38.

13. Kang KY. Effects of core muscle stability training on the weight distribution and stability of the elderly. J Phys Ther Sci 2015;27:3163-5.

14. Akuthota V, Nadler SF. Core strengthening. Arch Phys Med Rehabil 2004;85:S86-92.

15. Gringmuth $\mathrm{RH}$, Jackson $\mathrm{C}$. Therapeutic exercise for spinal segmental stabilization in low back pain: scientific basis and Clinical Approach. J Can Chiropr Assoc 2000;44:125.

16. Petrofsky JS, Cuneo M, Dial R, Pawley AK, Hill J. Core strengthening and balance in the geriatric population. J Appl Res 2005;5:423-33.

17. Najafabadi FP, Mahdavinejad R, Ghasemi G ali. Effect of 6 week of core stability on balance and quality of life in elderly women. Asian J Multidisciplin Stud 2014;2:113-7.

18. Bleakley CM, Charles D, Porter-Armstrong A, McNeill MDJ, McDonough SM, McCormack B. Gaming for health: a systematic review of the physical and cognitive effects of interactive computer games in older adults. J Appl Gerontol 2015;34: NP166-189.

19. Smith S, Schoene D. The use of exercise-based videogames for training and rehabilitation of physical function in older 
adults: current practice and guidelines for future research. Aging Health 2012;8:243-52

20. Taylor LM, Kerse N, Frakking T, Maddison R. Active video games for improving physical performance measures in older people: a meta-analysis. J Geriatr Phys Ther 2018;41:108-23.

21. Lamoth CJC, Caljouw SR, Postema K. Active video gaming to improve balance in the elderly. Stud Health Technol Inform 2011;167:159-64.

22. Heiden E, Lajoie Y. Games-based biofeedback training and the attentional demands of balance in older adults. Aging Clin Exp Res 2010;22:367-73.

23. Golpaigany M, Shavandi N, Mahdavi S, Hesari A, Alibakhshi E. The effect of core stabilization training program on elderly postural control. Spor Hekimliği Dergisi 2010;45:37-44.

24. Najafabadi FP, Mahdavinejad R, Ghasemi GA. Effect of 6 week of core stability on balance and quality of life in elderly women. Asia Pac J Multidiscip Res 2013;1:183-8

25. Suttanon P, Hill KD, Dodd KJ, Said CM. Retest reliability of balance and mobility measurements in people with mild to moderate Alzheimer's disease. Int Psychogeriatr 2011;23: 1152-9.

26. Bohannon RW, Steffl, M, Glenney SS, Green M, Prajerova K, Bunn J. The prone bridge test: performance, validity, and reliability among older and younger adults. J Bodyw Mov Ther 2018;22:385-9.

27. Sannicandro I. Effects of a core stability program on strength and balance skills in senior over 65. Int J Sci Res 2015;6: 939-43.

28. Wang D, Zhang J, Sun Y, Zhu W, Tian S, Liu Y. Evaluating the fall risk among elderly population by choice step reaction test. Clin Interv Aging 2016; 11:1075-82.

29. Steffen TM, Hacker TA, Mollinger L. Age- and gender-related test performance in community-dwelling elderly people: sixminute walk test, berg balance scale, timed up \& go test, and gait speeds. Phys Ther 2002;82:128-37.

30. Song G, Park EC. Effects of neck and trunk stabilization exercise on balance in older adults. J Kor Phys Ther 2016;28: 221-6.
31. Laver K, George S, Ratcliffe J, Quinn S, Whitehead C, Davies $\mathrm{O}$, et al. Use of an interactive video gaming program compared with conventional physiotherapy for hospitalised older adults: a feasibility trial. Disabil Rehabil 2012;34:1802-8.

32. Herndon CD, Decambre M, McKenna PH. Interactive computer games for treatment of pelvic floor dysfunction. J Urol 2001; 166:1893-8.

33. Lajoie Y. Effect of computerized feedback postural training on posture and attentional demands in older adults. Aging Clin Exp Res 2004;16:363-8.

34. Bisson E, Contant B, Sveistrup H, Lajoie Y. Functional balance and dual-task reaction times in older adults are improved by virtual reality and biofeedback training. Cyberpsychol Behav 2007;10:16-23.

35. Sonthikul C, Kaewmunee W, Sriwannawit P, Kasipan J, Khuatjit $\mathrm{N}$, Kimakhom D, et al. Comparative effect of a balance training program and core stabilization program on factors related to the prevention of falling in healthy middle-aged individuals: a double-blind randomized controlled clinical Trial. J Health Sci Med Res 2019;37:171-81.

36. Hodges PW, Richardson CA. Contraction of the abdominal muscles associated with movement of the lower limb. Physical Therapy 1997;77:132-42.

31. Willson J, Dougherty C, Ireland M, Davis I. Core stability and its relationship to lower extremity function and injury. J Am Acad Orthop Surg 2005;13:316-25.

38. Cho GH, Hwangbo G, Shin HS. The effects of virtual realitybased balance training on balance of the elderly. J Phys Ther Sci 2014;26:615-7.

39. Sato K, Kuroki K, Saiki S, Nagatomi R. Improving walking, muscle strength, and balance in the elderly with an exergame using kinect: a randomized controlled trial. Games Health $\mathrm{J}$ 2015;4:161-7.

40. Kaldırımcı M, Mohammadi M, Kazemi SE, Mızrak O, Tugrulhansam $\mathrm{C}$. The effect of aerobic exercise on improvement of motor functions in healthy elderly. Adv Appl Sci Res 2015;7: $21-7$. 